\title{
Good Manufacturing Practices production and analysis of a DNA vaccine against dental caries
}

\author{
Ya-ping YANG ${ }^{1, \#}$, Yu-hong $\mathrm{LI}^{1, \#}$, Ai-hua ZHANG ${ }^{2}$, Lan $\mathrm{BI}^{2}$, Ming-wen $\mathrm{FAN}^{1, *}$ \\ ${ }^{1}$ Key Laboratory for Oral Biomedical Engineering of Ministry of Education, School and Hospital of Stomatology, Wuhan University, \\ Wuhan 430079, China; ${ }^{2}$ Department of Immunology, Wuhan Institute of Biologic Products, Wuhan 430060, China
}

\begin{abstract}
Aim: To prepare a clinical-grade anti-caries DNA vaccine pGJA-P/VAX and explore its immune effect and protective efficacy against a cariogenic bacterial challenge.

Methods: A large-scale industrial production process was developed under Good Manufacturing Practices (GMP) by combining and optimizing common unit operations such as alkaline lysis, precipitation, endotoxin removal and column chromatography. Quality controls of the purified bulk and final lyophilized vaccine were conducted according to authoritative guidelines. Mice and gnotobiotic rats were intranasally immunized with clinical-grade pGJA-P/VAX with chitosan. Antibody levels of serum IgG and salivary SIgA were assessed by an enzyme-linked immunosorbent assay (ELISA), and caries activity was evaluated by the Keyes method. pGJA-P/VAX and pVAX1 prepared by a laboratory-scale commercial kit were used as controls.

Results: The production process proved to be scalable and reproducible. Impurities including host protein, residual RNA, genomic DNA and endotoxin in the purified plasmid were all under the limits of set specifications. Intranasal vaccination with clinical-grade pGJA-P/ VAX induced higher serum IgG and salivary SIgA in both mice and gnotobiotic rats. While in the experimental caries model, the enamel (E), dentinal slight (Ds), and dentinal moderate (Dm) caries lesions were reduced by $21.1 \%, 33.0 \%$, and $40.9 \%$, respectively. Conclusion: The production process under GMP was efficient in preparing clinical-grade pGJA-P/VAX with high purity and intended effectiveness, thus facilitating future clinical trials for the anti-caries DNA vaccine.
\end{abstract}

Keywords: dental caries; DNA vaccine; Good Manufacturing Practices

Acta Pharmacologica Sinica (2009) 30: 1513-1521; doi: 10.1038/aps.2009.152

\section{Introduction}

Dental caries, a widespread chronic infectious disease, occurs frequently in most people's lives ${ }^{[1]}$. If allowed to progress, it causes other complicated oral problems that result in discomfort, pain and even a decrease in quality of life. Multiple preclinical experiments and clinical trials have proven that application of anti-caries vaccines is a feasible and powerful preventive method ${ }^{[2-5]}$.

A DNA vaccine has advantages over traditional vaccines, such as persistent and stable expression of antigens in their native conformation, simultaneous stimulation of both $\mathrm{T}$ cells and B cells, and a safer and more stable profile in application and storage ${ }^{[6]}$. In light of advances in DNA vaccines and a public health imperative to prevent prevalent dental caries $^{[2]}$, we previously developed an anti-caries DNA vaccine

\footnotetext{
\# These authors contributed equally to this work.

* To whom correspondence should be addressed.

E-mail mingwenfan@yahoo.cn

Received 2009-06-11 Accepted 2009-09-15
}

pGJA-P/VAX ${ }^{[7]}$. The targeted fusion anti-caries DNA vaccine generates considerable specific immune responses in several experimental animals, such as mice ${ }^{[7]}$, hamsters ${ }^{[8]}$, rats ${ }^{[9]}$, and rabbits $^{[10]}$. Protection against attacks of cariogenic microorganisms has also been reported ${ }^{[9]}$. In larger animals such as rhesus monkeys ${ }^{[10]}$, immunization with pGJA-P/VAX also induces specific antibodies. Along with an initial safety profile ${ }^{[11]}$, this vaccine construct has shown promising prospects in the clinic. Translation of this laboratory research into clinical application requires more comprehensive and extensive clinical trials. An important premise of these trials is the availability of a large amount (milligrams or grams) of qualified DNA vaccine, which cannot be provided by conventional laboratory preparations, thus requiring large-scale industrial production.

In terms of manufacturing clinical-grade plasmids, the World Health Organization (WHO ${ }^{[12]}$ and US Food and Drug Administration (FDA $)^{[13,14]}$ have set guidelines and regulations. In China, the Guidelines for Preclinical Study of Prophylactic DNA Vaccine ${ }^{[15]}$ were issued by the Chinese State Food and Drug Administration (SFDA) in 2003 and these guidelines 
specifically describe the scale and process of the production as well as quality controls.

According to those international and national guidelines, the Good Manufacturing Practices (GMP) for pharmaceutical and biological products must also be applied to the production of DNA vaccines ${ }^{[16]}$. In our present study, we performed a large-scale production process under GMP conditions to manufacture the anti-caries DNA vaccine $\mathrm{pGJA-P/VAX}$ [referred to as pGJA-P/VAX(G) below]. Strict quality controls were emphasized. Detailed analyses of impurities in the final product were conducted according to the SFDA Guidelines, as well as WHO and FDA documents. The transfection activity, immunogenicity and protective effect of pGJA-P/VAX $(G)$ were also evaluated and compared with a vaccine prepared by a laboratory-scale commercial kit [referred to as pGJA-P/ VAX(L) below].

\section{Materials and methods Plasmids}

The anti-caries DNA vaccine $\mathrm{pGJA-P/VAX}$ was constructed in our laboratory as described before ${ }^{[10]}$. Briefly, pGJA-P comprised four protein-coding sequences: the signal peptide and extracellular regions of the human CTLA4 gene, the hinge and $\mathrm{Fc}$ regions of the human $\mathrm{Ig}_{\mathrm{r}}$ gene, the A-P region of pac gene from $S$ mutans, and the GLU region of $g t f B$ gene from $S$ mutans. The plasmid was then cloned into the FDA-approved vector pVAX1 (Invitrogen, Carlsbad, CA, USA) to create the pGJA-P/ VAX construct.

\section{GMP production of pGJA-P/VAX}

The general manufacturing conditions for the plasmid pGJA-P/VAX were in accordance with the requirements of Good Manufacturing Practices for both the pharmaceutical and biological products ${ }^{[17,18]}$. The whole production process generally consisted of five important steps: establishment of a Master Cell Bank (MCB) and Work Cell Bank (WCB), fermentation, pre-clarification, purification and further downstream processing. A flow sheet in Figure 1 provides an overview of the general production process.

\section{Establishment of MCB and WCB}

The MCB for pGJA-P/VAX was created by transformation of heat-shocked E coli JM109. The transformed cells were plated onto Luria-Bertani (LB) agar plates $(5 \mathrm{~g} / \mathrm{L}$ yeast extract, $10 \mathrm{~g} / \mathrm{L}$ tryptone, $10 \mathrm{~g} / \mathrm{L} \mathrm{NaCl}$, and $15 \mathrm{~g} / \mathrm{L}$ agar) containing $50 \mu \mathrm{g} /$ $\mathrm{mL}$ kanamycin (Lingfei, Wuhan, China) at $37^{\circ} \mathrm{C}$. Individual single colonies were isolated, cultured, and subjected to quality controls. The identified colony was then expanded into 100 $\mathrm{mL} \mathrm{LB}$ medium $(5 \mathrm{~g} / \mathrm{L}$ yeast extract, $10 \mathrm{~g} / \mathrm{L}$ tryptone, and 10 $\mathrm{g} / \mathrm{L} \mathrm{NaCl}$ ), also containing $50 \mu \mathrm{g} / \mathrm{mL}$ kanamycin, in a shaker at $280 \mathrm{r} / \mathrm{min}$ at $37^{\circ} \mathrm{C}$ for $8-10 \mathrm{~h}$. Sterile glycerol was added to the bacteria culture $(15 \% v / v)$, and aliquots of $1 \mathrm{~mL}$ were stored at $-70{ }^{\circ} \mathrm{C}$, forming the MCB. The WCB was generated by culturing bacteria from the MCB glycerol stocks overnight in LB medium with the presence of $50 \mu \mathrm{g} / \mathrm{mL}$ kanamycin. Each vial of the WCB stock was used only once and then

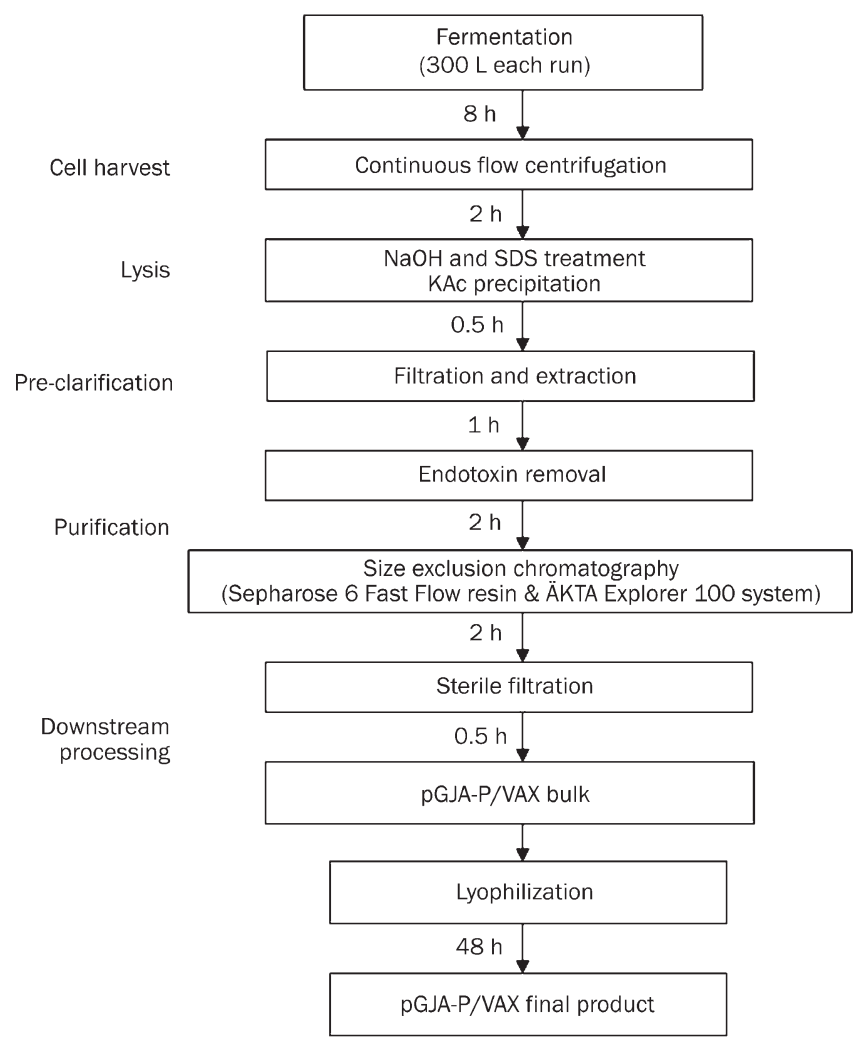

Figure 1. Process flow sheet for the production of $\operatorname{pGJA-P/VAX}(G)$. Approximate time for each step is shown to the left of the arrow. Abbreviations: $\mathrm{NaOH}$, sodium hydroxide; SDS, sodium dodecyl sulphate; $\mathrm{KAc}$, potassium acetate.

discarded.

\section{Fermentation and recovery}

One vial of the WCB was thawed and cultured in shake flasks containing $30 \mathrm{~mL}$ LB medium with $50 \mathrm{\mu g} / \mathrm{mL}$ kanamycin. After being cultured for $8 \mathrm{~h}$, bacteria were passaged at a ratio of 1:10 $(v / v)$ continuously for another two generations, and the volumes of media were $300 \mathrm{~mL}$ and $3000 \mathrm{~mL}$ for each generation. Finally, the resulting $3000 \mathrm{~mL}$ cultured broth was transferred into a $500 \mathrm{~L}$ fermentor (B.Braun, Melsungen, Germany) containing $300 \mathrm{~L}$ of medium that included: $8 \mathrm{~g} / \mathrm{L}$ yeast extract, $16 \mathrm{~g} / \mathrm{L}$ tryptone, $24 \mathrm{~mL} / \mathrm{L}$ glycerol, $0.33 \mathrm{~g} / \mathrm{L}$ glycine, $4 \mathrm{~g} / \mathrm{L} \mathrm{NaCl}, 7.08 \mathrm{~g} / \mathrm{L} \mathrm{Na}_{2} \mathrm{HPO}_{4}, 1.58 \mathrm{~g} / \mathrm{L} \mathrm{KH}_{2} \mathrm{PO}_{4}$, and $50 \mu \mathrm{g} /$ $\mathrm{mL}$ kanamycin. The fed-batch medium $(20 \mathrm{~L})$ contained: 100 $\mathrm{g} / \mathrm{L}$ yeast extract, $50 \mathrm{~g} / \mathrm{L}$ tryptone, $400 \mathrm{~mL} / \mathrm{L}$ glycerol, $5 \mathrm{~g} / \mathrm{L}$ glycine and $2 \mathrm{~g} / \mathrm{L} \mathrm{MgSO}_{4}$. The fermentation conditions were maintained as follows: temperature was controlled at $37^{\circ} \mathrm{C}$, airflow at $0.5 \mathrm{~m}^{3} / \mathrm{h}$, agitation at $375 \mathrm{r} / \mathrm{min}$, and $\mathrm{pH}$ at $7 \pm 0.3$. The fermentation was terminated at the late $\log$ phase $(8 \mathrm{~h}$ post inoculation), and bacteria were harvested by continuous flow centrifugation at $12000 \mathrm{r} / \mathrm{min}$.

\section{Lysis and pre-clarification}

The bacterial paste was weighed, and each gram of wet bac- 
teria was sufficiently suspended in $8 \mathrm{~mL}$ Solution P1 (0.05 $\mathrm{mol} / \mathrm{L}$ Tris- $\mathrm{HCl}, 0.01 \mathrm{~mol} / \mathrm{L}$ EDTA, $\mathrm{pH}$ 8.0) (the volumes referred in this section represent the amount of solution for each gram of wet bacteria). Next, $8 \mathrm{~mL}$ Solution P2 (0.4 $\mathrm{mol} / \mathrm{L} \mathrm{NaOH}, 2 \% \mathrm{SDS}$, mixed equally before use) was added to the previous suspension, and the combination mixed quickly and uniformly by low-shear agitation for 15-30 s, and left to sit at room temperature for $7 \mathrm{~min}$. Cellular debris, genomic DNA and proteins were precipitated by $15 \mathrm{~mL}$ prechilled Solution P3 [5 mol/L KAc, mixed with glacial acetic acid at 82:18 (v/v) before use]. The mixture was left at room temperature for $30 \mathrm{~min}$, and the precipitate was then removed by filtration.

\section{Endotoxin removal}

Endotoxin was removed with endotoxin removal solutions (HaiGui Biosciences Co, Ltd, Shanghai, China), according to the manufacturer's instructions. Briefly, Solution ED1 and ED2 were sequentially added to the crude plasmid-containing solution at a ratio of 1:10 $(v / v)$ and centrifuged separately for $30 \mathrm{~min}$ at room temperature. Solution $\operatorname{ED} 3(1: 1, v / v)$ was then added and mixed sufficiently for 2-3 min. After a centrifugation at $3000 \mathrm{r} / \mathrm{min}$ for $15 \mathrm{~min}$, the supernatant was transferred to a new endo-free tube. Addition of ED3 and subsequent centrifugation were conducted three times to remove the endotoxin as much as possible.

\section{Size exclusion chromatography (SEC)}

SEC was then carried out for further purification. An XK50/30 column with a maximum bed volume of $2000 \mathrm{~mL}$ (Amersham Pharmacia Biotech, Freiburg, Germany) was packed with cross-linked agarose matrices Sepharose 6 Fast Flow (GE Healthcare, Diegem, Belgium). ÄKTA Explorer 100 system (Amersham Pharmacia Biotech, Freiburg, Germany) was connected as a real-time detecting system. The packed column was equilibrated with $2-4$ bed volumes of $0.02 \mathrm{~mol} / \mathrm{L}$ phosphate-buffered saline (PBS). When the system baseline appeared steady, the plasmid-containing solution was loaded at $20 \%$ of the bed volume. After all the solution had passed through the column, elution buffer (0.02 mol/L PBS, pH 7.2) was loaded to elute the plasmid. Absorbance at $260 \mathrm{~nm}$ and $280 \mathrm{~nm}\left(A_{260}\right.$ and $\left.A_{280}\right)$ was simultaneously detected, and the fractions corresponding to the plasmid were collected at the first absorption peak.

\section{Downstream processing}

The eluates were pooled, and samples were taken to be subjected to quality controls. After being proven qualified, the purified plasmid solution was mixed with mannitol, sterilefiltered and then filled into sterile endo-free microtubes. Lyophilization was finally performed for a better storage condition and a longer shelf life.

\section{Quality controls}

Strict quality controls were performed according to SFDA Guidelines. All chemicals used were of analytical grade.

\section{Identification of MCB and WCB}

The MCB and WCB were both testified an $E$ coli origin by shape of bacteria colony, gram staining and a biochemical IMViC test ${ }^{[19]}$. MCB were cultured for 50 continuous passages on LB agar plates, and samples from certain generations (ie, the 20th generation, the 40th generation, and the 50th generation) were taken. Sequencing was conducted by Sangon Biological Engineering Technology \& Services Co Ltd (Shanghai, China). LB agar plates with or without kanamycin $\left(\mathrm{Kan}^{+} /\right.$ $\mathrm{Kan}^{-}$) were used to perform the stability examination. Briefly, dilutions of samples were plated on $\mathrm{Kan}^{-}$plate and cultured at $37^{\circ} \mathrm{C}$ for $24 \mathrm{~h}$. One hundred individual colonies were then replicated onto $\mathrm{Kan}^{+}$plates. After being cultured for another $24 \mathrm{~h}$, colonies were counted, and the ratio of colony number on the $\mathrm{Kan}^{+}$plate to that on the Kan- plate indicated the stability characteristics of the plasmid towards antibiotics. Doubledecker agar plates were used to detect possible contamination of bacteriophage. Briefly, LB agar medium was added with diluted bacteria samples at $50{ }^{\circ} \mathrm{C}$ and then poured onto the top of a pre-solidified agar plate. After being cultured at $30^{\circ} \mathrm{C}$ for $6-12 \mathrm{~h}$, the upper layer of the double-decker agar plate was checked for phage plaque. Restriction enzyme digestion and $0.8 \%$ agarose gel electrophoresis (AGE) were performed to confirm the identity of the plasmid. Single identification digestion was made using only one restriction enzyme, Kpn I (Takara Bio Inc, Otsu, Japan) or Nhe I (Takara Bio Inc, Otsu, Japan), both of which produced one fragment $7349 \mathrm{bp}$ in size; or Xho I (Takara Bio Inc, Otsu, Japan), which produced two fragments of $2273 \mathrm{bp}$ and $5076 \mathrm{bp}$. Double digestion was done by applying both Xho I and Nhe I to produce three fragments of 2273 bp, 2077 bp, and 2999 bp (Figure 2A).

\section{Quality control of bulk purified pGJA-P/VAX(G)}

For the bulk purified pGJA-P/VAX $(\mathrm{G})$, impurities including host protein, residual RNA, genomic DNA and endotoxin were analyzed by methods suggested in the authoritative guidelines $^{[13,15]}$. Briefly, the contaminated protein of the $E$ coli host cell was tested with a commercial ELISA kit (Cygnus Technologies, Plainville, MA) according to the manufacturer's instructions. Possible contamination of residual RNA was detected on AGE. Genomic DNA of the host $E$ coli in the purified plasmid was assessed by a Southern slot blot analysis ${ }^{[20]}$. The plasmid topology was analyzed by high-performance liquid chromatography (HPLC) ${ }^{[21]}$. The endotoxin content was checked by observing the gel clotting caused by the interaction of endotoxin in diluted samples with the Limulus amebocyte lysate (Cape Cod Associates, Cape Cod, MA, USA), and the detection level for this method was $0.125 \mathrm{EU} / \mathrm{mL}$.

\section{Quality control of final lyophilized pGJA-P/VAX(G)}

For the lyophilized vaccine, the content of residual water was tested with the Karl Fischer Method ${ }^{[22,23]}$ using an automatic titrator (756 KF Coulometer; Metrohm, Herisau, Switzerland). The reconstitution profile was checked by resolving the lyophilized vaccine in sterile Water for Irrigation (WFI) at room temperature. The time for resolving was recorded, and the 
A
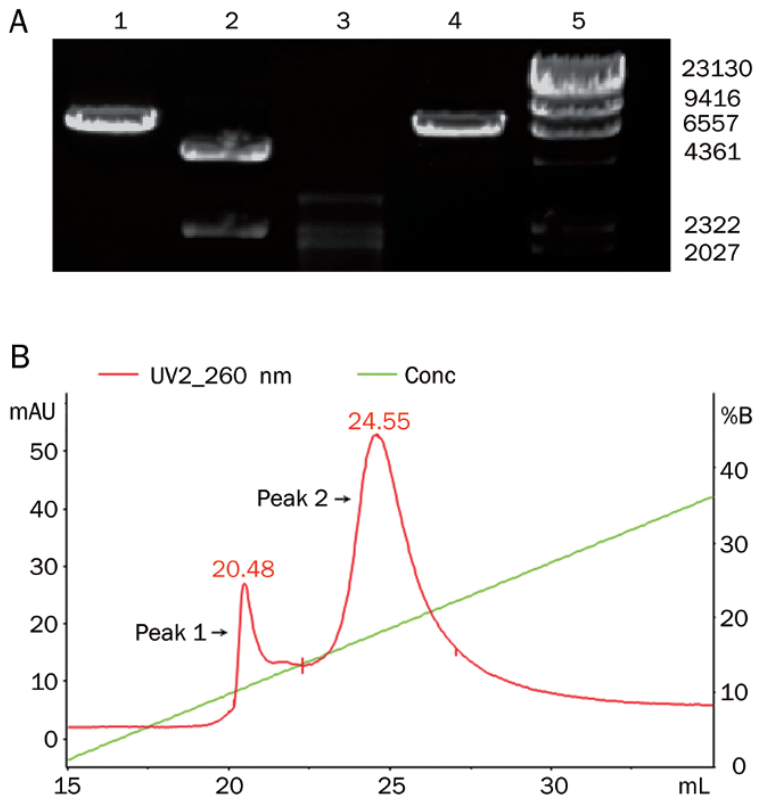

Figure 2. AGE and HPLC analysis of purified pGJA-P/VAX(G). (A) AGE after restriction endonuclease digestion. pGJA-P/VAX(G) digested by Kpn I (Lane 1); Xho I (Lane 2); both Xho I and Nhe I (Lane 3); Nhe I (Lane 4). Lane 5 represents the DNA marker AHind III. (B)HPLC analysis of purified pGJA-P/ $\operatorname{VAX}(G)$. Peak 1: open circular topology; Peak 2: supercoiled topology.

appearance of the resulting solution was detected visually. The sterility status was evaluated by culturing diluted samples of the resolved lyophilized vaccine on Fluid Thioglycollate Medium at both $20-25^{\circ} \mathrm{C}$ and $30-35^{\circ} \mathrm{C}$ and on modified Martin Medium at $20-25^{\circ} \mathrm{C}$, all for 14 days.

\section{Fusion protein expression in cultured cells}

Expression of the fusion protein by pGJA-P/VAX $(\mathrm{G})$ was tested in a transient transfection assay using Lipofectamin2000 (Invitrogen, Carlsbad, CA, USA), according to the manufacturer's instructions. Briefly, Chinese hamster ovary cells $(\mathrm{CHO}$, purchased from the Chinese Center for Type Culture Collection, CСТCC, Wuhan, China) were plated onto 12-well plates containing glass slides at a cell density of $3 \times 10^{5}$ cells $/ \mathrm{mL}$. When an $80 \%-90 \%$ confluent was achieved, the cells were incubated with DNA-Lipofectamin2000 complexes for 4-6 h and then cultured for another 24-48 h with Dulbecco modified Eagle medium (DMEM; HyClone, Logan, Utah, USA) supplemented with $10 \%$ fetal bovine serum (FBS; Gibco Laboratories, Grand Island, NY). Expression of recombinant fusion protein in $\mathrm{CHO}$ was evaluated with a fluorescent immunoassay with avidin-biotin-Cy3 Complex (Boster, Wuhan, China). The slides were fixed, blocked and then incubated with anti-PAc antibody or anti-Glu antibody at $4{ }^{\circ} \mathrm{C}$ overnight. They were then incubated with biotinylated goat anti-mouse IgG and avidin-biotin-Cy3 complex in turn and finally viewed under a fluorescence microscope.

\section{Animal immunizations}

For animal experiments, pGJA-P/VAX was prepared by two different methods. One was the large-scale industrial production under GMP conditions as described above, while the other was a laboratory-scale preparation using a commercial Endofree Plasmid Mega Kit (Qiagen, Hilden, Germany) according to the manufacturer's instructions. The vector pVAX1 prepared by the kit was also included in the animal experiments to act as a control.

DNA-chitosan complexes were formed as described previously ${ }^{[9,24]}$. Briefly, $0.05 \mathrm{~mol} / \mathrm{L}$ sodium sulfate solution containing $200 \mu \mathrm{g} / \mathrm{mL}$ of plasmid was preheated to $55^{\circ} \mathrm{C}$ and dropped into an equal volume of chitosan solution $(0.02 \%$ in $1 \%$ ethanoic acid, $\mathrm{pH} 5.5)$ under a magnetic vortex. The mixture was left for $2 \mathrm{~h}$ at room temperature and then freeze dried. The complexes were dissolved in saline prior to immunization.

The animal experiments in this study were reviewed and approved by the Review Board of Hubei Medical Laboratory Animal Center. Experiment 1: Eighteen four-to-six-week-old female Balb/c mice were randomly divided into three groups: pGJA-P/VAX(G)-chitosan complex (Group A), pGJA-P/ VAX(L)-chitosan complex (Group B) and pVAX1-chitosan complex (Group C). The mice were intranasally immunized at week 0 and week 2 . Serum and saliva were collected prior to the first immunization and biweekly after the immunizations until week 12. All the samples were stored at $-70{ }^{\circ} \mathrm{C}$ until tested. Experiment 2: The experimental caries rat model was established as previously described ${ }^{[25]}$. Eighteen specific pathogen-free (SPF) female Wistar rats were weaned at $18 \mathrm{~d}$ of age and bred with a cariogenic diet Keyes $2000^{[25]}$. To temporarily suppress the oral flora and facilitate colonization with $S$ mutans, antibiotics (ampicillin, chloramphenicol, and carbenicillin $1.0 \mathrm{~g} / \mathrm{kg}$ diet) were added to the diet for three consecutive days (on days 20-22). The rats were orally challenged daily with $2 \times 10^{9}$ colony forming units (CFU) of $S$ mutans Ingbritt $C$ on days $24-26$, applying swabs presoaked with the bacterial suspension. Oral swabs were taken from the occlusal surfaces of each rat to check for the bacteria, before and after the infection. When the bacteria successfully colonized the tooth surface, the rats were divided in groups and immunized using the same protocols as in Experiment 1. The rats were sacrificed at day 70 , serum and saliva were collected, and the mandibles were obtained for recording the caries scores.

\section{Antibody analysis}

An enzyme-linked immunosorbent assay (ELISA) was performed to determine the specific antibody levels as described previously ${ }^{[26]}$. Briefly, each well of 96-well microtiter plates was coated with recombinant PAc or Glu $(10 \mu \mathrm{g} / \mathrm{mL}$ in carbonate buffer, $\mathrm{pH}$ 9.6) overnight at $4{ }^{\circ} \mathrm{C}$. After being blocked with PBS containing 3\% BSA and $0.05 \%$ Tween-20 the next day, serum or saliva in optimal dilution were incubated at $37^{\circ} \mathrm{C}$ for $2 \mathrm{~h}$. The bound antibodies were then detected by horseradish peroxidase conjugated goat anti-mouse/rat IgG (Southern Biotech, Birmingham, AL, USA) or IgA (Southern Biotech, Birmingham, AL, USA). The reaction was followed by incubation with O-phenylenediamine substrate with $\mathrm{H}_{2} \mathrm{O}_{2}$ 
at $37^{\circ} \mathrm{C}$ for $15 \mathrm{~min}$, and then finally stopped by $2 \mathrm{~mol} / \mathrm{L}$ of $\mathrm{H}_{2} \mathrm{SO}_{4}$. Absorbance at $490 \mathrm{~nm}\left(A_{490}\right)$ was then recorded. A standard curve was established for each plate, at which point, the wells were coated by purified unconjugated goat antimouse/rat IgG (Boster, Wuhan, China) or IgA (Bethyl Laboratories, Montgomery, TX, USA), and mouse/rat reference serum (Bethyl Laboratories, Montgomery, TX, USA) in serial dilutions were then added. All samples were tested in duplicate wells. The concentrations of antibodies and total Ig in test samples were calculated by interpolation on standard curves. To normalize for variation in total Ig content in the saliva samples, the levels of SIgA antibody activity are expressed as the ratio of specific (anti-PAc or anti-Glu) IgA per total IgA levels.

\section{Caries assessment}

All rats were sacrificed at the end of the experiment. The mandibles were removed, cleaned and stained with murexide $(0.4 \%$ in $70 \%$ ethanol). After the mandibles were hemisectioned, the buccal, sulcal, and proximal molar caries were scored according to the Keyes method ${ }^{[27]}$. The reduction percentages of the enamel, dentinal slight, and dentinal moderate caries lesions were calculated by "[(Caries score of Group C Caries score of Group A/B)/Caries score of Group C]*100\%".

\section{Statistical analysis}

SPSS 10.0 software (SPSS, Inc, Chicago, IL, USA) was used to perform statistical analyses. The differences in antibody levels and caries scores among groups were determined by one-way analysis of variance (ANOVA). A value of $P<0.05$ was considered significant.

\section{Results}

\section{Identification of MCB and WCB}

The MCB and WCB demonstrated smooth, ivory-colored, and moderate-sized colonies on the agar plates. Results of gram staining (red, short-rod shaped, and gram-negative) and the biochemical IMViC tests (positive, positive, negative, and negative) verified an $E$ coli origin of the MCB and WCB. The products of restriction endonuclease digestion were identical with the construction map as expected (Figure 2A). Sequences of the plasmid were consistent with the pac and $g t f B$ genes from $S$ mutans. The WCB subjected to 50 passages was shown to express the plasmid stably. On the double-decker agar plates, no phage plaque was detectable, indicating that both the MCB and WCB were free from bacteriophage contamination.

\section{Quality control of purified pGJA-P/VAX(G) bulk}

The quality control results of pGJA-P/VAX $(G)$ from three separate batches are shown in Table 1 , and relative authoritative standards for each test items are also listed. The physical appearance and content of the impurities generally conformed to the demands of the guidelines from either the SFDA or FDA. The restriction patterns obtained for pGJA-P/VAX(G) were identical to those of pGJA-P/VAX(L) and in accordance with the construction map. The content of the host protein detected by the commercial kit varied in the range of 9-66 $\mathrm{ng} / \mathrm{mg}$, well below the national specifications $(\leq 1 \mu \mathrm{g} / \mathrm{mg}$ plasmid). In HPLC and AGE, no contaminated host RNA was detected, and most of the purified plasmid demonstrated a supercoiled topology (Figure 2B). Linear plasmid was not seen in any of the samples.

\section{Quality control of final lyophilized pGJA-P/VAX(G)}

The final lyophilized pGJA-P/VAX(G) demonstrated a uniform, white, and fluffy powder. It was able to be completely dissolved in WFI within $1 \mathrm{~min}$, resulting in a clear colorless solution. Residual water in lyophilized vaccine conformed to the SFDA specifications. Possible contamination of aerobe, anaerobe and mycoplasma was excluded because cultured samples of the final vaccine on relative mediums for 14 days showed no growth of these microorganisms. Quality controls of the lyophilized vaccine are summarized in Table 2.

\section{Expression of recombinant fusion protein in vitro}

The cytoplasm of pGJA-P/VAX(G)-transfected CHO cells was positively stained with fluorescent red after incubation with anti-PAc or anti-Glu antibody, whereas no such specific prod-

Table 1. Quality control performed on produced bulk plasmid including set specifications.

\begin{tabular}{|c|c|c|c|c|}
\hline \multirow[t]{2}{*}{ Test items } & \multirow[t]{2}{*}{ Specifications } & \multicolumn{3}{|c|}{ Results } \\
\hline & & Batch 1 & Batch 2 & Batch 3 \\
\hline Appearance & Clear, colorless solution ${ }^{\#, *}$ & Conforms & Conforms & Conforms \\
\hline $\mathrm{pH}$ & $7.2 \pm 0.5^{\#, *}$ & 7.14 & 7.33 & 7.28 \\
\hline Identity & Consistent with construction map m, $^{\#}$ & Conforms & Conforms & Conforms \\
\hline Purity & $A_{260} / A_{280}>1.75^{\#, *}$ & 1.83 & 1.88 & 1.79 \\
\hline Host protein & $\leq 1 \mu \mathrm{g} / \mathrm{mg}$ plasmid ${ }^{\#} ;(<1 \%)^{*}$ & 66 ng/mg & 42 ng/mg & $9 \mathrm{ng} / \mathrm{mg}$ \\
\hline Host genomic DNA & $\leq 2 \mu g / m g$ plasmid $;(<1 \%)^{*}$ & Conforms & Conforms & Conforms \\
\hline Host RNA & Undetectable in $\mathrm{AGE}^{\#, *}$ & Conforms & Conforms & Conforms \\
\hline Endotoxin & $\leq 10 \mathrm{EU} / \mathrm{mg}$ plasmid ${ }^{\#} ;\left(\leq 40 \mathrm{EU} / \mathrm{mg}\right.$ plasmid ${ }^{*}$ & $<5 \mathrm{EU} / \mathrm{mg}$ & $<5 \mathrm{EU} / \mathrm{mg}$ & $<5 \mathrm{EU} / \mathrm{mg}$ \\
\hline The ratio of supercoiled topology & $\geq 90 \%{ }^{\#} ;(>80 \%)^{*}$ & $84.39 \%$ & $82.97 \%$ & $89.3 \%$ \\
\hline
\end{tabular}

\# Specifications from Guidelines for Preclinical Study of Prophylactic DNA Vaccine (SFDA 2003).

* Specifications from Guidance for Industry: Considerations for Plasmid DNA Vaccines for Infectious Disease Indications (FDA 2007). 
Table 2. Quality control performed on final lyophilized product including set specifications.

\begin{tabular}{|c|c|c|c|c|}
\hline \multirow[t]{2}{*}{ TTest items } & \multirow[t]{2}{*}{ Specifications $\#$} & \multicolumn{3}{|c|}{ Results } \\
\hline & & Batch 1 & Batch 2 & Batch 3 \\
\hline Appearance & White, freeze-dried cake & Conforms & Conforms & Conforms \\
\hline Reconstitution & $\begin{array}{l}\text { Complete, leaving no visible residue as undissolved matter and } \\
\text { resulting in a clear, colorless solution }\end{array}$ & Conforms & Conforms & Conforms \\
\hline Residual water content & $\leq 3 \%$ & $1.3 \%$ & $0.9 \%$ & $1.8 \%$ \\
\hline Sterility & Sterile & Conforms & Conforms & Conforms \\
\hline
\end{tabular}

\# Specifications from Guidelines for Preclinical Study of Prophylactic DNA Vaccine (SFDA 2003) and Guidance for Industry: Considerations for Plasmid DNA Vaccines for Infectious Disease Indications (FDA 2007).
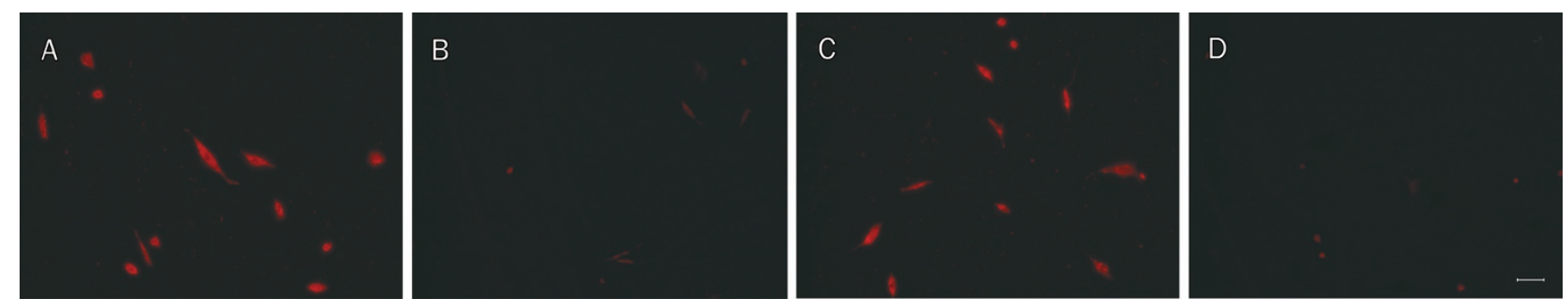

Figure 3. Expression of recombinant fusion proteins in $\mathrm{CHO}$ cells. (A and $\mathrm{B}$ ) $\mathrm{CHO}$ cells transfected with pGJA-P/VAX(G) (A) or pVAX1 (B) detected by antiPAc antibody; (C and D) CHO cells transfected with pGJA-P/VAX(G) (C) or pVAX1 (D) detected by anti-Glu antibody. Scale bar, $10 \mu \mathrm{m}$.

ucts could be found in cells transfected with pVAX1 vector. The transfection results indicated that pGJA-P/VAX $(G)$ had the potential to express both PAc and Glu protein in eukaryotic cells (Figure 3).

\section{Antibody analysis}

Mice in both Group A and Group B induced significantly higher anti-PAc and anti-Glu serum IgG and salivary SIgA levels than those in Group C $(P<0.01)$. No significant difference was detected between Group A and Group B $(P>0.05)$ (Figure 4).

About 40 days after the first immunization, anti-PAc and anti-Glu serum IgG and salivary SIgA levels induced by gnotobiotic rats in both Group A and Group B were significantly higher than those in Group $C(P<0.01)$. No significant difference was detected between Group A and Group B $(P>0.05)$ (Figure 5).

\section{Caries protection}

Rats in both Group A and Group B displayed significantly fewer enamel (E), dentinal slight (Ds) and dentinal moderate $(\mathrm{Dm})$ lesions than those in Group $\mathrm{C}(P<0.01)$. The reduction percentages of E, Ds and Dm of Group A were 21.1\%, $33.0 \%$, and $40.9 \%$; whereas in Group B, the percentages were $25.0 \%, 26.5 \%$, and $47.0 \%$. There were no significant differences between Group A and Group B $(P>0.05)$ (Figure 6).

\section{Discussion}

Rapid progresses in the field of gene-based technology, such as DNA vaccination or gene therapy, require large quantities (milligrams or grams) of clinical-grade plasmid ${ }^{[28]}$. Large-scale production and purification of plasmid is usually a result of combination and optimization of several unit operations. In the present study, we developed a scalable and reproducible production process by combining common unit operations such as alkaline lysis, precipitation, endotoxin removal and column chromatography. The industrial production process proved to be efficient in manufacturing hundreds of milligrams of clinical-grade anti-caries DNA vaccine, pGJA-P/ VAX.

A reliable production process should be able to be scaled up. In preliminary studies, we have tested the fermentation at different volumes. The results showed that the weight of the wet bacteria harvested at the end of fermentation positively correlated with the fermentation volume (data not shown). Therefore, we finally conducted the fermentation at $300 \mathrm{~L}$ each run. A single fermentation for $8 \mathrm{~h}$ resulted in $3.8 \mathrm{~kg}$ of wet bacteria, and about $780 \mathrm{mg}$ of purified pGJA-P/VAX(G) was obtained after purification. In previous reports, larger fermentation volumes in a single run have never been derived. Quaak et $a l^{[29]}$ conducted a 10-L fermentation to obtain $156 \mathrm{mg}$ of purified plasmid, while Diogo and colleagues yielded $142 \mathrm{mg}$ of purified plasmid with a 4.5-L fermentation ${ }^{[21]}$. Compared with the research mentioned, we were able to obtain more plasmids in a single run. Furthermore, the feasibility of fermentation in such a large volume proved that the upstream production process can be successfully scaled up.

Endotoxin, derived from the cell membrane of the gramnegative bacteria, may elicit a wide variety of pathophysiological effects, even at a low concentration ${ }^{[30]}$. Plasmids produced 

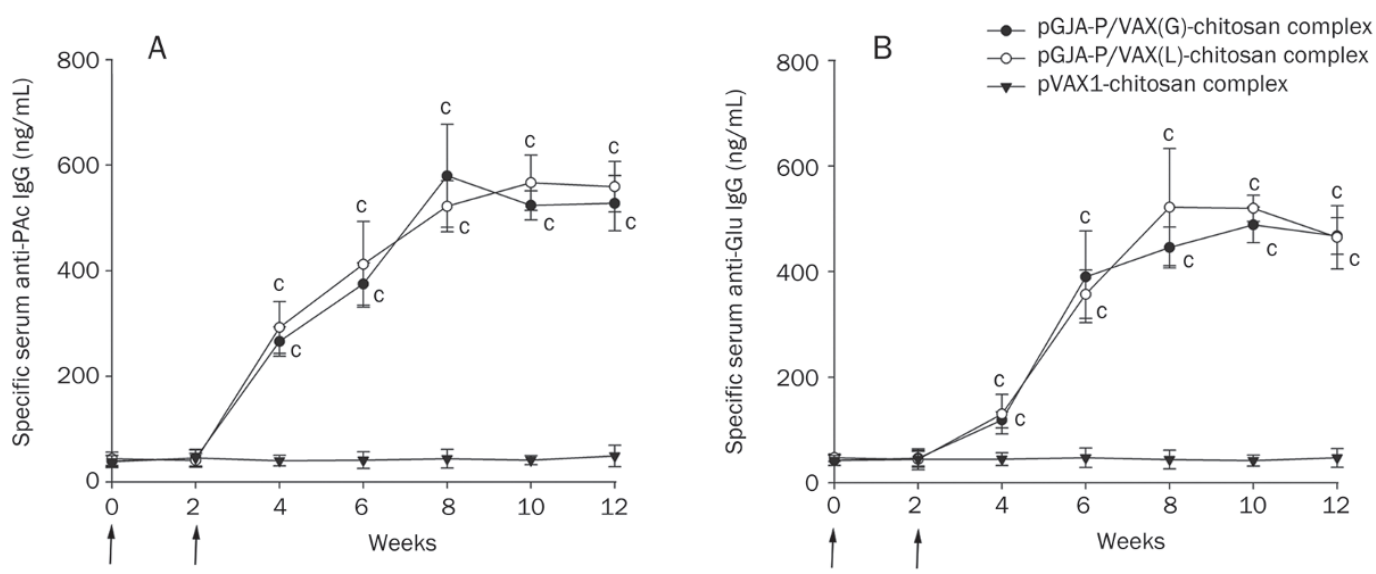

Figure 4. Antibody levels of mice intranasally immunized with $\mathrm{pGJA-P/VAX(G)-chitosan}$ complex (Group A), pGJA-P/ $\operatorname{VAX}(\mathrm{L})$-chitosan complex (Group B), and pVAX1chitosan complex (Group C).
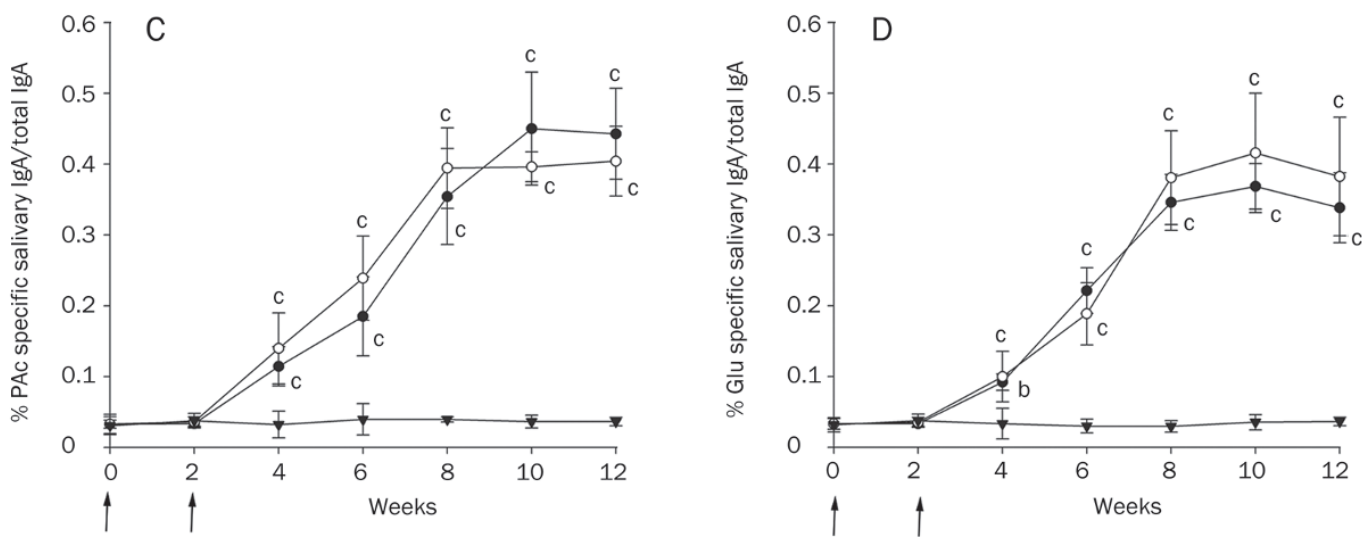

Serum and saliva samples were collected biweekly for ELISA. Data are expressed as the mean $\pm S D$. Symbols for statistical significance. ${ }^{\mathrm{b}} P<0.05,{ }^{\mathrm{c}} P<0.01$ vs Group C. The arrows stand for the time points of immunization. (A) Serum anti-PAc IgG antibody levels; (B) Serum anti-Glu IgG antibody levels; (C) Salivary anti-PAc SIgA antibody levels; (D) Salivary anti-Glu SIgA antibody levels.

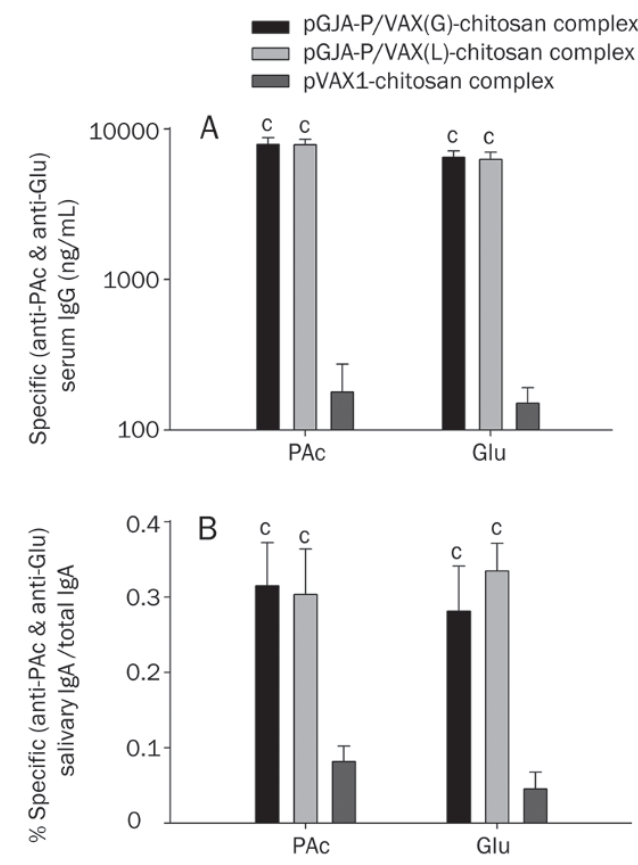

Figure 5. Antibody levels of rats intranasally immunized with pGJA-P/ $\operatorname{VAX}(G)$ - chitosan complex (Group A), pGJA-P/VAX(L)-chitosan complex (Group B), and pVAX1-chitosan complex (Group C). Serum and saliva samples were collected at d 70 for ELISA. Data are expressed as the mean \pm SD. ${ }^{C} P<0.01$ vs Group C. (A) Serum anti-PAc and anti-Glu IgG antibody levels; (B) Salivary anti-PAc and anti-Glu SlgA antibody levels.

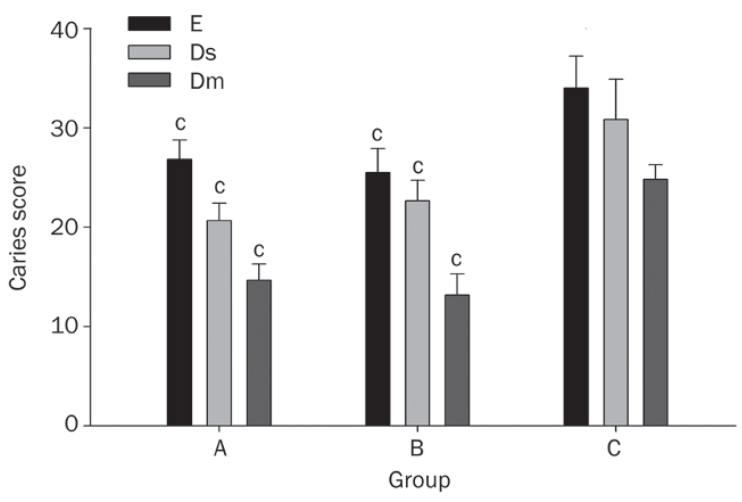

Figure 6. The enamel (E), dentinal slight (Ds) and dentinal moderate $(\mathrm{Dm})$ caries scores of rats immunized with pGJA-P/VAX(G)-chitosan complex (Group A), pGJA-P/VAX(L)-chitosan complex (Group B) and pVAX1chitosan complex (Group C). The caries lesions were scored by the Keyes method. The results are expressed as mean $\pm S D$. Symbols for statistical significance: ${ }^{\circ} P<0.01$ vs Group C.

by $E$ coli are always contaminated with endotoxin, the content of which should be strictly limited, as almost all the guidelines require ${ }^{[13,15,16]}$. A variety of chromatographic methods have been used for endotoxin removal, including hydrophobic interaction ${ }^{[21]}$, affinity chromatography with polymixin $\mathrm{B}^{[31]}$ and gel filtration ${ }^{[32]}$. In our study, we used non-ionic deter- 
gents from HaiGui Biosciences Co, Ltd, which specifically bind endotoxin to conduct two-phase separation for endotoxin removal. After pretreatment with ED1 and ED2 as well as three extractions by ED3, most endotoxin was removed from the crude solution. This procedure also acted as a conditioning step for subsequent chromatography.

Size exclusion chromatography (SEC) was done in our study. It is a simple and reproducible method for plasmid purification that separates the plasmid from protein, RNA, host DNA, and endotoxin in a single chromatographic step $^{[33,34]}$. The commercial matrices Sepharose 6 Fast Flow gel filtration media were developed specifically to meet the highthroughput demands of industrial process separations. It permits high flow rates that in turn give good resolution in minimal time. In our study, the completion of SEC only took two hours, showing great advantages over time-consuming anion exchange chromatography ${ }^{[29]}$. During this step, the formulation buffer was also able to be simultaneously changed into an appropriate buffer (PBS in this study) without any additional dialysis or downstream processing ${ }^{[21]}$.

After SEC, the collected elution was sampled and then subjected to quality controls. The content of impurities including the host genomic DNA, RNA, protein and endotoxin in the purified bulk was analyzed and all conformed to the authoritative specifications. However, our result for the ratio of supercoiled topology in the purified plasmid was slightly lower than SFDA specifications. Compared to those laboratory-scale preparations, appearance of non-supercoiled topology is much more frequent in large-scale productions. When large volumes of fermentation broth or viscous lysates are handled in industrial production process ${ }^{[35]}$, reactions such as mixing or precipitation usually become insufficient due to technical and mechanical difficulties, making fluid shearing forces unavoidable in any stage of the production. Once a breakage happens to the backbone of polynucleotide, non-supercoiled plasmids such as open circular or even linear topologies appear. Precautions and possible solutions have been suggested to delineate or avoid the shearing forces ${ }^{[35]}$. In the present production process, we applied gentle operations instead of vigorous agitating or mixing, and low shearing filtration was conducted to replace conventional centrifugation.

International guidelines and/or regulations have recommended that the fraction of plasmid in supercoiled conformation be included in the bulk release criteria. A percentage equal to or greater than $90 \%$ is preferred by the 2003 SFDA Guidelines ${ }^{[15]}$. However, in the latest special document released by the FDA in 2007 for industries, a minimum specification for supercoiled plasmid was set at $80 \%^{[13]}$. It was stressed that different release criteria and specifications may be set as long as the plasmid has the immunogenicity or other intended biological activities. Furthermore, both SFDA and FDA guidelines require researchers to develop potency assays that include in vitro measures of transfection ability or in vivo assays of DNA vaccine immunogenicity. In our study, we tested the efficacy of purified pGJA-P/VAX $(G)$ both in vitro and in vivo. The resultant plasmid was shown to express both PAc and Glu protein in cultured cells. Moreover, in the animal experiments, it indeed induced notable specific immune responses and provided anti-caries protection.

Intranasal immunization has been widely applied in anticaries vaccines ${ }^{[36-38]}$, due to easier administration, lower doses of antigens required and activation of both systemic and mucosal immune responses. However, delivery of genes by the intranasal route is always hampered by poor plasmid uptake across the epithelium. In order to increase plasmid uptake and limit degradation, chitosan, a polysaccharide comprising copolymers of glucosamine and $\mathrm{N}$-acetylglucosamine, was used as an intranasal delivery system for pGJA-P/ $\mathrm{VAX}^{[9,24]}$. In our previous studies, we prepared DNA-chitosan microparticles by a complex coacervation process ${ }^{[24]}$, and experiments in vitro demonstrated that the DNA-chitosan complex was stable and plasmid DNA could be released constantly from these complexes. Our results here show that pGJA-P/VAX (G) with the chitosan intranasal delivery system could significantly increase the levels of anti-PAc and anti-Glu antibody in mice and gnotobiotic rats. Specific IgG in serum and SIgA in saliva of mice were shown to begin increasing from week 4 , achieve a peak at about week 6 or 8 and still remain at a high level until week 12 . The antibody levels induced by pGJA-P/VAX $(\mathrm{G})$ were similar to those of pGJA-P/ $\operatorname{VAX}(\mathrm{L})$ and were also comparable to our previous studies ${ }^{[7]}$. In gnotobiotic rats, intranasal delivery of pGJA-P/VAX $(G)$ was efficient in elevating specific antibodies associated with lower caries scores. The protective effect of anti-caries vaccines is believed to be the result of blocking adhesion-receptor interaction by the induced antibodies, especially specific SIgA in the oral cavity ${ }^{[39]}$. Specifically, anti-PAc SIgA blocks sucrose-independent and sucrose-dependent attachment of $S$ mutans to tooth surfaces; anti-Glu SIgA inhibits water-insoluble glucan synthesis and reduces the accumulation of cariogenic microorganisms ${ }^{[38]}$. The fusion anti-caries DNA vaccine pGJA-P/VAX shows great advantages by inducing both antiPAc and anti-Glu SIgA simultaneously, thus inhibiting dental plaque formation at the attachment and accumulation stage, respectively. When the bacterial factor of caries development becomes incompetent, caries lesions decrease as indicated by lower caries scores.

In summary, we prepared the clinical-grade anti-caries DNA vaccine pGJA-P/VAX through a scalable and reproducible GMP production, the end product of which is able to induce a significant immune response and anti-caries protection. The easy availability of pGJA-P/VAX $(G)$ through large-scale production will greatly facilitate application of this vaccine in future clinical trials.

\section{Acknowledgements}

The project was supported by grants from the National Key Technology R\&D Program of China (№ 2007BAI28B04) and the National Natural Science Foundation of China (№ 30600707). 


\section{Author contribution}

Ming-wen FAN designed the research and revised the paper; Ya-ping YANG, Yu-hong LI, Ai-hua ZHANG, and Lan BI performed the research; Ya-ping YANG and Yu-hong LI wrote the paper.

\section{References}

1 Bowen WH. Do we need to be concerned about dental caries in the coming millennium? Crit Rev Oral Biol Med 2002; 13: 126-31. .

2 Taubman MA, Nash DA. The scientific and public-health imperative for a vaccine against dental caries. Nat Rev Immunol 2006; 6: 555-63.

3 Smith DJ. Dental caries vaccines: prospects and concerns. Crit Rev Oral Biol Med 2002; 13: 335-49.

4 Gregory RL. Dental caries vaccines: science and status. Compendium, (1994 OCT) 15 (10) 1282, 1284, 1286 passim;quiz 1294.

5 Russell MW, Childers NK, Michalek SM, Smith DJ, Taubman MA. A Caries Vaccine? The state of the science of immunization against dental caries. Caries Res 2004; 38: 230-5.

6 Cui Z. DNA Vaccine. Adv Genet 2005; 54: 257-89.

7 Xu QA, Yu F, Fan MW, Bian Z, Chen Z, Fan B, et al. Immunogenicity and persistence of a targeted anti-caries DNA vaccine. J Dent Res 2006; 85: 915-8.

8 Zhang F, Li YH, Fan MW, Jia R, Xu QA, Guo JH, et al. Enhanced efficacy of CTLA-4 fusion anti-caries DNA vaccines in gnotobiotic hamsters. Acta Pharmacol Sin 2007; 28: 1236-42.

9 Xu QA, Yu F, Fan MW, Bian Z, Chen Z, Peng B, et al. Protective efficacy of a targeted anti-caries DNA plasmid against cariogenic bacteria infections. Vaccine 2007; 25: 1191-5.

10 Jia R, Guo JH, Fan MW, Bian Z, Chen Z, Fan B, et al. Immunogenicity of CTLA4 fusion anti-caries DNA vaccine in rabbits and monkeys. Vaccine 2006; 24: 5192-200.

11 Liu C, Fan M, Xu Q, Li Y. Biodistribution and expression of targeted fusion anti-caries DNA vaccine PGJA-P/VAX in mice. J Gene Med 2008; 10: 298-305.

12 Robertson J, Griffiths E. WHO guidelines for assuring the quality of DNA vaccines. Biologicals 1998; 26: 205-12.

13 FDA. Guidance for Industry: Considerations for Plasmid DNA Vaccines for Infectious Disease Indications. Biotechnology Law Report 2007; 26: 641-8.

14 FDA. Points to consider on plasmid DNA vaccine for preventive infectious disease indications. 1996.

15 SFDA. Guidelines for Preclinical Study of Prophylactic DNA Vaccine. 2003.

16 WHO. Guidelines for assuring the quality and nonclinical safety evaluation of DNA vaccines. WHO Technical Report 2007; Series № 941.

17 WHO. Good manufacturing practices for pharmaceutical products. WHO Technical Report 2003; Series № 908.

18 WHO. Good manufacturing practices for biological products. WHO Technical Report 1992; Series № 822.

19 Stuart CA, Griffin AM, Baker ME. Relationships of Coliform Organisms. J Bacteriol 1938; 36: 391-410.

20 Diogo MM, Queiroz JA, Monteiro GA, Martins SA, Ferreira GN, Prazeres DM. Purification of a cystic fibrosis plasmid vector for gene therapy using hydrophobic interaction chromatography. Biotechnol Bioeng 2000; 68: 576-83.

21 Diogo MM, Ribeiro SC, Queiroz JA, Monteiro GA, Tordo N, Perrin P, et al. Production, purification and analysis of an experimental DNA vaccine against rabies. J Gene Med 2001; 3: 577-84.

22 ScholZ E. Karl Fischer Titration: determination of water. BerlinHeidelerg: Springer-Verlag; 1984.

23 May JC, Grim E, Wheeler RM, West J. Determination of residual moisture in freeze-dried viral vaccines: Karl Fischer gravimetric and thermogravimetric methodologies. J Biol Stand 1982; 10: 249-59.

24 Li YH, Fan MW, Bian Z, Chen Z, Zhang Q, Yang HR. Chitosan-DNA microparticles as mucosal delivery system: synthesis, characterization and release in vitro. Chin Med J (Engl) 2005; 118: 936-41.

25 Navia JM. Animal models in dental research. Tuscaloosa: University of Alabama Press; 1977. p 280-307.

26 Zhang P, Jespersgaard C, Lamberty-Mallory L, Katz J, Huang Y, Hajishengallis $G$, et al. Enhanced immunogenicity of a genetic chimeric protein consisting of two virulence antigens of Streptococcus mutans and protection against infection. Infect Immun 2002; 70: 6779-87.

27 Keyes PH. Dental caries in the molar teeth of rats. II. A method for diagnosing and scoring several types of lesions simultaneously. J Dent Res 1958; 37: 1088-99.

28 Urthaler J, Ascher C, Wohrer H, Necina R. Automated alkaline lysis for industrial scale cGMP production of pharmaceutical grade plasmidDNA. J Biotechnol 2007; 128: 132-49.

29 Quaak SG, van den Berg JH, Toebes M, Schumacher TN, Haanen $\mathrm{JB}$, Beijnen JH, et al. GMP production of pDERMATT for vaccination against melanoma in a phase I clinical trial. Eur J Pharm Biopharm 2008; 70: 429-38.

30 Magalhaes PO, Lopes AM, Mazzola PG, Rangel-Yagui C, Penna TC, Pessoa A Jr. Methods of endotoxin removal from biological preparations: a review. J Pharm Pharm Sci 2007; 10: 388-404.

31 Montbriand PM, Malone RW. Improved method for the removal of endotoxin from DNA. J Biotechnol 1996; 44: 43-6.

32 Ferreira GN, Cabral JM, Prazeres DM. Development of process flow sheets for the purification of supercoiled plasmids for gene therapy applications. Biotechnol Prog 1999; 15: 725-31.

33 Horn NA, Meek JA, Budahazi G, Marquet M. Cancer gene therapy using plasmid DNA: purification of DNA for human clinical trials. Hum Gene Ther 1995; 6: 565-73.

34 Stadler J, Lemmens R, Nyhammar T. Plasmid DNA purification. J Gene Med 2004; 6 Suppl 1: S54-66.

35 Ferreira GN, Monteiro GA, Prazeres DM, Cabral JM. Downstream processing of plasmid DNA for gene therapy and DNA vaccine applications. Trends Biotechnol 2000; 18: 380-8.

36 Jespersgaard C, Hajishengallis G, Huang Y, Russell MW, Smith DJ, Michalek SM. Protective immunity against Streptococcus mutans infection in mice after intranasal immunization with the glucanbinding region of $S$ mutans glucosyltransferase. Infect Immun 1999; 67: 6543-9.

37 Fontana M, Dunipace AJ, Stookey GK, Gregory RL. Intranasal immunization against dental caries with a Streptococcus mutansenriched fimbrial preparation. Clin Diagn Lab Immunol 1999; 6: 405-9.

38 Koga T, Oho T, Shimazaki Y, Nakano Y. Immunization against dental caries. Vaccine 2002; 20: 2027-44.

39 Hajishengallis G, Nikolova E, Russell MW. Inhibition of Streptococcus mutans adherence to saliva-coated hydroxyapatite by human secretory immunoglobulin A (S-IgA) antibodies to cell surface protein antigen I/II: reversal by IgA1 protease cleavage. Infect Immun 1992; 60: 5057-64. 